\title{
Feber under fødsel og antibiotikabehandling - en kvalitetssikringsstudie
}

\section{Kristin Bøhn}

Fagutviklingsjordmor

Fødeavdelingen, Oslo universitetssykehus, Ullevål

\section{Siv Merethe Amundsen}

Jordmor

Fødeavdelingen, Oslo universitetssykehus, Ullevål

\section{Katariina Laine}

Avdelingsleder, overlege og førsteamanuensis

Kvinneklinikken, Oslo universitetssykehus og Avdeling for helseledelse og helseøkonomi, Universitetet i Oslo

\section{Dorte Hvidtjørn}

Jordmor og førsteamanuensis II

Universitetet i Sørøst-Norge og Aarhus Universitetshospital, Danmark

\section{Aase Devold Pay}

Assisterende avdelingsleder og førsteamanuensis

Fødeavdelingen, Oslo universitetssykehus og Fakultet for helsevitenskap, Oslomet storbyuniversitetet

Kvalitet

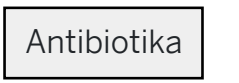

\section{Fødsel}

Feber

Tverrsnittsstudie

Sykepleien Forskning 202116 (86080) (e-86080)

DOI: 10.4220/Sykepleienf.2021.86080

\section{Sammendrag}

Bakgrunn: Feber under fødsel defineres som kroppstemperatur $\geq 38^{\circ} \mathrm{C}$ og forekommer ved omtrent 7 prosent av fødsler til termin. Tilstanden gir $\varnothing \mathrm{kt}$ risiko for maternell og neonatal sykelighet og dødelighet. Korrekt bruk av antibiotika kan redusere forekomsten av alvorlige utfall for mor og barn. 
Hensikt: Kartlegge forekomst av feber under fødsel og bruk av antibiotika med denne indikasjonen ved Fødeavdelingen Ullevål på Oslo universitetssykehus samt vurdere om bruken av antibiotika var i henhold til klinikkens prosedyre.

Metode: Gjennomgang av journaler til pasienter med fødsel til termin som var innlagt på fødeavdelingen i perioden 1.-30. april 2018.

Resultat: Feber under fødsel (intrapartum feber) var registrert hos 67 av 552 pasienter (12 prosent). 99 pasienter (18 prosent) mottok behandling med feberreduserende medikamenter og/eller antibiotika grunnet feber. Av disse fikk 53 penicillin (54 prosent) grunnet mistanke om infeksjon. Kriteriene etter gjeldende prosedyre for profylaktisk antibiotikabehandling ble oppfylt hos 38 av de 53 pasientene som fikk penicillin ( 72 prosent). Penicillin i kombinasjon med gentamycin ble gitt til 21 av 99 pasienter (21 prosent) med indikasjon klinisk chorioamnionitt (betennelse i føtale membraner). Av disse 21 pasientene var det 15 (71 prosent) som oppfylte kriteriene for behandling.

Konklusjon: Vi fant en høyere forekomst av intrapartum feber enn beskrevet i litteraturen. Journalgjennomgangen viste at bruken av antibiotika var i henhold til prosedyren på flere områder, men at det var utfordringer knyttet til overbehandling.

Feber i fødsel (intrapartum feber, definert som kroppstemperatur $\geq 38^{\circ} \mathrm{C}$ ) er en klinisk diagnose som krever nøye oppfølging og behandling for å forebygge alvorlige komplikasjoner for helsen til mor og barn (1$5)$.

Nyere kohortstudier viser en forekomst på rundt sju prosent ved fødsler til termin ( $\geq 37$. svangerskapsuke) $(2,5)$. Intrapartum feber kan skyldes infeksiøse eller ikke-infeksiøse årsaker, og konsekvenser for mor og barn vil være avhengig av årsaken (2).

Feber ved ikke-infeksiøse tilstander er forbundet med $\varnothing \mathrm{kt}$ risiko for mor og barn, som inkluderer operativ vaginal forløsning og keisersnitt $(2,3,6)$, Apgar-skår $<7$ ved 5 minutters alder, behov for resuscitering, kramper samt fire ganger høyere risiko for hjerneskade hos barnet $(7,8)$. Infeksiøs feber forsterker ytterligere risikoen for komplikasjoner $(2,9)$. 


\section{Risikofaktorer for intrapartum feber}

Risikofaktorer for intrapartum feber er blant annet førstegangsfødende, langvarig fødselsforl $\varnothing p$, for tidlig vannavgang og gjentatte vaginalunders $\varnothing$ kelser $(3,5,10$, 11).

Gravide med nevnte risikofaktorer har videre en forhøyet risiko for å utvikle intraamniotisk infeksjon (IAI), altså inflammasjon av hinner, morkake og fostervann forårsaket av bakteriell infeksjon, og/eller få epiduralanestesi, som er de to vanligste årsakene til intrapartum feber $(1,2)$. I fravær av en eksisterende feberlidelse, som luftveisinfeksjon, vil de fleste gravide som får feber i fødsel, behandles med bredspektret antibiotika på grunn av antatt IAI.

I «Veileder i fødselshjelp» (12) og lokale prosedyrer anbefales antibiotikabehandling ved mistanke om IAI og snarlig planlegging av forløsning. Oppstår feber uten tegn på infeksjon, foreslås generelt feberreduserende tiltak med paracetamol og væske peroralt eller intraven $\varnothing$ st.

Ved vedvarende feber der ikke andre kliniske tegn til infeksjon er til stede, anbefales bruk av penicillin profylaktisk, mens ved feber med to av fem tilleggskriterier (se tabell 1 for tilleggskriterier) anbefales bruk av bredspektret antibiotika.

Feber er det viktigste kliniske tegnet på IAI, og ingen konkrete laboratoriefunn eller kliniske tegn skiller pålitelig mellom IAI og epiduralrelatert feber $(2,11,13)$. Etiologien bak epiduralrelatert feber er uavklart, med det er identifisert underliggende ikke-infeksiøse inflammatoriske prosesser (7).

Den lave terskelen for diagnostisering og antibiotikabehandling av IAI kan derfor føre til overbehandling ettersom mange av disse pasientene senere viser fravær av infeksiøs årsak $(3,5,6,9)$. 


\section{Hensikten med studien}

Hensikten med studien var å identifisere omfanget av intrapartum feber og kartlegge bruken av antibiotika med denne indikasjonen i en gitt tidsperiode ved Fødeavdelingen Ullevål på Oslo universitetssykehus (OUS).

Studien har i tillegg et kvalitetssikringsperspektiv da vi unders $\varnothing$ kte i hvilken grad prosedyren for antibiotikabehandling etterleves ved fødeavdelingen. Etterlevelse av prosedyrer er et viktig ledd i å kvalitetssikre den helsehjelpen som tilbys.

Tabell 1. Lokal prosedyre om feber under fødsel og chorioamnionitt

\begin{tabular}{|c|c|c|}
\hline & Kriterier & Intervensjon \\
\hline 1) Intrapartum feber & Temperatur $\geq 38^{\circ} \mathrm{C}$ & $\begin{array}{l}\text { Generell behandling: } \\
\text { Paracetamol } 1 \mathrm{~g} \text {, } \\
1000 \mathrm{ml} \text { Ringer-Acetat, } \\
\text { senke romtemperaturen }\end{array}$ \\
\hline 2) Mistanke om infeksjon & $\begin{array}{l}\text { Manglende respons på 1) etter 20-30 } \\
\text { minutter }\end{array}$ & $\begin{array}{l}\text { Penicillin G 1,2 g x } 4 \text { IV, } \\
\text { oppstart minst } 1 \text { time før fødsel }\end{array}$ \\
\hline 3) Klinisk chorioamnionitt & $\begin{array}{l}\text { Manglende respons på } 1 \text { ) og minst to } \\
\text { av følgende tilleggskriterier: } \\
\text { - maternell tachykardi } \\
\geq 100 \text { slag per minutt } \\
\text { - føtal takykardi } \\
\geq 160 \text { slag per minutt } \\
\text { - maternell leukocytose } \\
\geq 15 \times 109 / / \\
\text { - } \varnothing \text { mhet over uterus } \\
\text { - illeluktende fostervann }\end{array}$ & $\begin{array}{l}\text { Penicillin G } 1,2 \mathrm{~g} \times 6 \mathrm{IV} \text { og gentamycin } \\
5 \mathrm{mg} / \mathrm{kg} \times 1 \mathrm{IV}\end{array}$ \\
\hline
\end{tabular}

\section{Metode}

\section{Design og utvalg}

Studien var en deskriptiv tverrsnittsstudie med en retrospektiv journalgjennomgang av alle fødslene i perioden 1.-30. april 2018 ved Fødeavdelingen Ullevål, OUS. Fødeavdelingen Ullevål består av to fødeenheter og én lavrisikoenhet.

Pasienter i aktiv fødsel, det vil si regelmessige rier og mormunnsåpning $\geq 3 \mathrm{~cm}$ (14), med svangerskap til termin ble benyttet til å beregne forekomsten av intrapartum feber og antibiotikabehandling med denne indikasjonen. 
Detaljerte opplysninger ble innhentet fra den elektroniske fødejournalen Partus, pasientjournalen DIPS og fosterovervåkningssystemet STAN Viewer (Neoventa), som inkluderte informasjon om maternelle, obstetriske og neonatale karakteristika, utfall og behandlingsmetoder.

Vi kvalitetssikret dataene ved manuell gjennomgang av alle journalene uten hensyn til prosedyrekoder eller medisinske diagnoser relatert til feber, infeksjon og antibiotikabehandling i aktiv fødsel.

Materialet ble strukturert og deskriptivt analysert. Vi presenterer resultatene med median og variasjonsbredde for kontinuerlige data og med frekvens og prosentandel for kategoriske data. Studien ble godkjent av Personvernombudet ved OUS 5. februar 2019 (saksnummer 19/03137).

Vi registrerte og analyserte dataene anonymisert. Det var ingen koplingsn $\varnothing k k e l$ eller registrering av personnummer eller navn. Da studien var en kvalitetssikringsstudie, var den ikke fremleggingspliktig for Regionale komiteer for medisinsk og helsefaglig forskningsetikk (REK).

\section{Resultater}

I 2018 var fødselsantallet ved Ullevål sykehus 6861, noe som utgjorde 12,5 prosent av alle fødsler i Norge (55 072) (15). Av totalt 621 fødsler i studieperioden ble 69 fødsler ekskludert (figur 1).

De resterende 552 hadde ved oppstart av aktiv fødsel passert uke $37+0$. Journalgjennomgangen viste at 99 av 552 pasienter ( 18 prosent) mottok generell febersenkende medikamentell behandling og/eller antibiotika grunnet mistanke om infeksjon i fødsel eller IAI. En dokumentert temperatur $\geq 38^{\circ} \mathrm{C}$ ble funnet hos 67 av $55^{2}$ pasienter (12 prosent). 
Maternelle, obstetriske og neonatale karakteristika hos pasienter som mottok medikamentell behandling $i$ forbindelse med forhøyet kroppstemperatur ( $\mathrm{n}=99$ ), er presentert i tabell 2.

Figur 1. Seleksjonsprosess

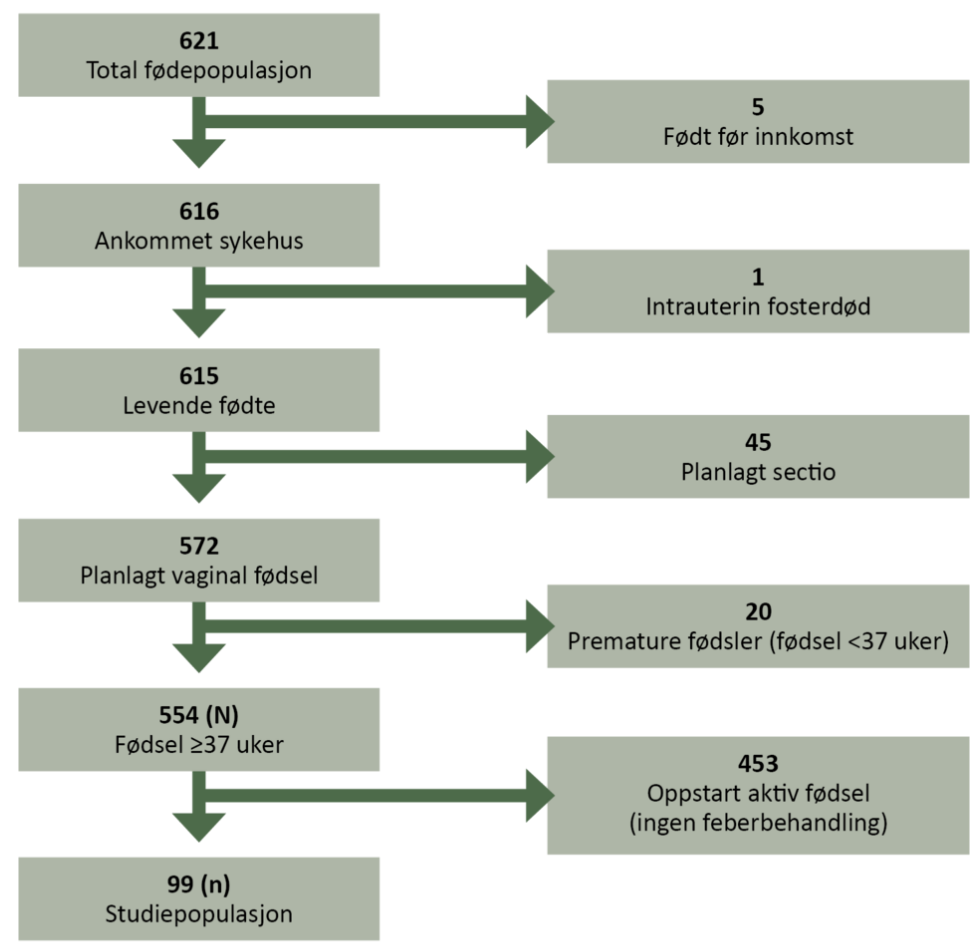


Tabell 2. Maternelle, obstetriske og neonatale karakteristika hos pasienter som mottok medikamentell behandling i forbindelse med forh $\varnothing$ yet kroppstemperatur i studieperioden $(n=99)$

\begin{tabular}{|c|c|}
\hline Maternelle faktorer & Feberbehandlet $(n=99)$ Median [intervall], Antall (\%) \\
\hline Alder & $32[22-43]$ \\
\hline Førstegangsf $\varnothing$ dende & $86(87)$ \\
\hline Svangerskapsvarighet i dager & $283[261-294]$ \\
\hline \multicolumn{2}{|l|}{ Obstetriske faktorer } \\
\hline Fødselsstart, spontan/indusert & $52(53) / 47(47)$ \\
\hline Fødselsvarighet stadium 1 & $7[1-17]$ \\
\hline Fødselsvarighet stadium $1+2$ & $9[1-19]$ \\
\hline Vannavgang, antall timer & $13[0-88]$ \\
\hline Misfarget fostervann & $26(26)$ \\
\hline Epiduralanestesi & $89(90)$ \\
\hline Epiduralanestesi, antall timer & $9[2-30]$ \\
\hline Epiduralanestesi, varighet, antall $<7$ timer / $\geq 7$ timer & $20(22) / 69(78)$ \\
\hline Antall vaginalunders $\varnothing$ kelser etter innkomst & $11[3-22]$ \\
\hline Antall vaginalunders $\varnothing$ kelser f $\varnothing$ r temperaturintervensjon & $6[0-16]$ \\
\hline Oksytocinstimulert & $86(87)$ \\
\hline Vaginal fødsel spontan & $52(53)$ \\
\hline Operativ vaginal fødsel & $32(32)$ \\
\hline Akutt keisersnitt & $15(15)$ \\
\hline Blødning $>1000 \mathrm{ml}$ & $19(19)$ \\
\hline Antibiotikabehandling postpartum & $2(2)$ \\
\hline \multicolumn{2}{|l|}{ Neonatale faktorer } \\
\hline Apgar $<7$ etter 5 minutter & $2(2)$ \\
\hline Overflyttet nyfødtintensiv & $3(3)$ \\
\hline Antibiotikabehandling på nyfødtintensiv & $2(2)$ \\
\hline
\end{tabular}

\section{Intrapartum feber og generell behandling}

Generell behandling av feber (feberreduserende behandling: paracetamol kombinert med intraven $\varnothing \mathrm{s}$ væske) ble gitt til 92 av 99 pasienter (93 prosent) (tabell 3). Hos de resterende sju kvinnene var det dokumentert at fem fikk intraven øs væske med feber som indikasjon uten at paracetamol var dokumentert.

I to tilfeller ble penicillin gitt på bakgrunn av feber uten at det var dokumentert feberreduserende behandling. Ved oppstarten av generell behandling hadde 44 pasienter temperatur under $38,0^{\circ} \mathrm{C}$, mens 48 hadde temperatur mellom $38,0^{\circ} \mathrm{C}$ og $38,7^{\circ} \mathrm{C}$. 
Tabell 3. Pasienter som mottok feberreduserende behandling i studieperioden

\begin{tabular}{|c|c|c|}
\hline \multicolumn{3}{|l|}{ Feberreduserende behandling ( $n=99$ ) } \\
\hline 92/99 (93 \%) & $5 / 99(5 \%)$ & $2 / 99(2 \%)$ \\
\hline $\begin{array}{l}\text { Generell behandling: paracetamol } 1 \mathrm{~g}+\text { intraven } \varnothing \mathrm{s} \\
\text { væske, Ringer-Acetat (RA) }\end{array}$ & RA & Ukjent \\
\hline $48 / 92(52 \%)$ & 44/92 (48 \%) & \\
\hline Oppfylte kriterier for generell behandling & Oppfylte ikke kriterier for generell behandling & \\
\hline Temperatur ved oppstart $\left[38,0-38,7^{\circ} \mathrm{C}\right]$ & Temperatur ved oppstart $\left[37,1-37,9^{\circ} \mathrm{C}\right]$ & \\
\hline
\end{tabular}

\section{Mistanke om infeksjon og profylaktisk antibiotikabehandling}

Penicillin ble gitt til 53 av 99 pasienter (54 prosent) ved mistanke om infeksjon (tabell 4). Av disse oppfylte 38 av 53 (72 prosent) kriteriene. Av de 15 pasientene som ikke oppfylte kriteriene, ble det hos fem startet med penicillin før effekten av generell behandling ble vurdert.

Åtte pasienter hadde temperatur $<38^{\circ} \mathrm{C}$, mens to ikke hadde registrert temperatur. Den høyeste temperaturen som ble målt under fødsel hos disse pasientene, var $38,1^{\circ} \mathrm{C}$. Tre pasienter oppfylte krav til penicillin uten å bli behandlet med dette.

\section{Klinisk chorioamnionitt og behandling med penicillin og gentamycin}

Tjueen av 53 pasienter (40 prosent) fikk penicillin $\mathrm{i}$ kombinasjon med gentamycin (tabell 4). Av disse var det 15 av 21 (71 prosent) som fikk behandling i tråd med retningslinjene.

Av de seks pasientene som ikke møtte kriteriene, hadde to temperaturer under $38^{\circ} \mathrm{C}$. De tre andre hadde temperatur på $38,0-38,1^{\circ} \mathrm{C}$ og null eller én tilleggsfaktor. Hos én var ikke temperaturen registrert. Alle pasientene som skulle ha behandling, fikk det. 
Tabell 4. Antibiotikabehandling hos pasienter som fikk feberreduserende behandling $\mathrm{i}$ studieperioden

\begin{tabular}{|c|c|c|c|c|c|}
\hline \multicolumn{6}{|c|}{ Antibiotikabehandling hos pasienter som fikk feberreduserende behandling ( $n=99$ ) } \\
\hline \multicolumn{4}{|l|}{$53 / 99$ (54 \%) } & \multirow{2}{*}{\multicolumn{2}{|c|}{$\begin{array}{l}46 / 99(46 \%) \\
\text { Ingen antibiotika }\end{array}$}} \\
\hline \multicolumn{4}{|c|}{ Penicillin (PC) $1,2 \mathrm{~g} \times 4$} & & \\
\hline \multicolumn{2}{|l|}{$38 / 53(72 \%)$} & \multicolumn{2}{|c|}{$15 / 53(28 \%)$} & $43 / 46(93 \%)$ & $3 / 46(7 \%)$ \\
\hline \multicolumn{2}{|c|}{ Oppfylte kriterier for behandling } & \multicolumn{2}{|c|}{ Oppfylte ikke kriterier for behandling } & & $\begin{array}{l}\text { Oppfylte } \\
\text { kriterier }\end{array}$ \\
\hline \multicolumn{2}{|c|}{$\begin{array}{l}\text { Temperatur ved oppstart } \\
{\left[38,0-38,9^{\circ} \mathrm{C}\right]}\end{array}$} & \multicolumn{2}{|c|}{$\begin{array}{l}\text { Temperatur ved oppstart } \\
{\left[37,2-38,1^{\circ} \mathrm{C}\right]}\end{array}$} & $\begin{array}{l}\text { Effekt av generell } \\
\text { behandling eller/og } \\
\text { temperatur }<38^{\circ} \mathrm{C}\end{array}$ & Fikk ikke PC \\
\hline \multicolumn{3}{|l|}{$21 / 53(40 \%)$} & $32 / 53(60 \%)$ & & \\
\hline \multicolumn{3}{|c|}{ Penicillin + gentamycin 5mg/kg } & $\begin{array}{l}\text { Ikke behandlet } \\
\text { for klinisk } \\
\text { chorioamnionitt }\end{array}$ & & \\
\hline $15 / 21$ (71 \%) & $5 / 21(24 \%)$ & $1 / 21(5 \%)$ & $32(100 \%)$ & & \\
\hline $\begin{array}{l}\text { Oppfylte kriterier } \\
\text { for behandling }\end{array}$ & $\begin{array}{l}\text { Oppfylte ikke } \\
\text { kriterier }\end{array}$ & & & & \\
\hline $\begin{array}{l}\text { Temperatur } \\
\text { ved oppstart } \\
{\left[38,0-38,6^{\circ} \mathrm{C}\right]}\end{array}$ & $\begin{array}{l}\text { Temperatur } \\
\text { ved oppstart } \\
{\left[37,6-38,1^{\circ} \mathrm{C}\right]}\end{array}$ & Ukjent & Korrekt behandling & & \\
\hline
\end{tabular}

\section{Diskusjon}

Resultatene viser at intrapartum feber kompliserte nesten en av åtte fødsler til termin, da 67 av 552 pasienter (12 prosent) hadde en temperatur $\geq 38^{\circ} \mathrm{C} \mathrm{i}$ aktiv fødsel. Totalt mottok 99 av 552 (18 prosent) en eller annen form for medisinsk behandling på bakgrunn av forhøyet temperatur. Etterlevelse av prosedyre ble i stor grad fulgt, men det var utfordringer knyttet til overbehandling.

\section{«Resultatene viser at intrapartum feber kompliserte nesten en av åtte fødsler til termin.»}

Internasjonale studier viser en samlet forekomst av intrapartum feber på rundt sju prosent $(1,2,5)$. Dette tallet er noe lavere enn det vi fant i vår studie. Ulike studiedesign, studiepopulasjoner, forekomster av risikofaktorer samt obstetrisk praksis varierer mellom studiene, slik at forekomsten ikke nødvendigvis er sammenliknbar. 
I vår studie var majoriteten av pasientene som mottok feberbehandling, førstegangsfødende (87 prosent) og fikk epiduralanestesi (90 prosent). Studier viser at paritet og epiduralbruk er forbundet med intrapartum feber $(6,8,11)$.

Det er mulig at den høye forekomsten av feber i vår populasjon delvis kan forklares ut fra høy bruk av epiduralanestesi og høy andel førstegangsfødende. Epiduralrelatert feber rapporteres med en forekomst på mellom 13 og 33 prosent hos førstegangsfødende og ses i sammenheng med lengre varighet av fødsel, flere intervensjoner og mer utstrakt bruk av epiduralanestesi $(8,11,16)$.

\section{«Det er mulig at den høye forekomsten av feber $i$ vår populasjon delvis kan forklares ut fra høy bruk av epiduralanestesi og høy andel førstegangsfødende.»}

I tillegg var vår populasjon representert med en rekke kjente risikofaktorer: Omtrent halvparten (47 prosent) ble indusert, hvorav en tredjedel på indikasjonen langvarig vannavgang. Nesten to tredjedeler ble oksytocinstimulert (riestimulert) grunnet langvarig fødselsforløp og et hyppig antall vaginalunders $\varnothing$ kelser.

Flere studier viser at gjentatte vaginalunders $\varnothing$ kelser er en selvstendig risikofaktor for intrapartum feber og IAI og fant at antallet vaginale unders $\varnothing$ kelser korrelerer med prosentvis $\varnothing$ kning i andel IAI $(17,18)$.

En betydelig andel pasienter ble forløst med vakuum og/eller tang (32 prosent) eller akutt keisersnitt (15 prosent). Resultatet samsvarer med studier som viser at intrapartum feber gir $\varnothing \mathrm{kt}$ risiko for obstetriske intervensjoner $(3,9)$. 
Feber og intrauterin inflammasjon kan være årsaken til dysfunksjonelle kontraksjoner, langvarige fødselsforløp og alvorlige blødninger etter fødsel, samtidig som det gir $\varnothing \mathrm{kt}$ risiko for neonatal hypoksi. Neonatale utfall var gode med få barn med Apgar $<7$ ved 5 minutters alder (2/99) og/eller behov for antibiotikabehandling (2/99).

Ingen av barna som ble overflyttet til nyf $\varnothing$ dtintensivavdelingen, var i gruppen med klinisk chorioamnionitt. Hos to av barna hadde mor fătt penicillin, og hos ett kvalifiserte mor for penicillin, men fikk det ikke. Den lave andelen av neonatal sepsis i febergruppen samsvarer med flere studier som fant at antatt IAI senere viser fravær av infeksiøs årsak $(2,5,9$, 19).

\section{Generell behandling og antibiotikabruk}

Generell behandling med paracetamol og intraven $\varnothing s$ væske ble gitt til 92 av 99 (93 prosent), til tross for at bare omtrent halvparten ( 48 av 92, 52 prosent) oppfylte kravene etter klinikkens prosedyrer. En hensikt om å forebygge intrapartum feber i forbindelse med stigende kroppstemperatur i fødsel kan muligens forklare hvorfor disse pasientene mottok denne behandlingen.

Selv om paracetamol og intravenøs væske anses å ha få bivirkninger, finner man liten evidens i litteraturen på at paracetamol har forebyggende eller feberreduserende effekt på mors temperatur i fødsel $(20,21)$.

\section{«Majoriteten fikk korrekt behandling ved mistanke om infeksjon.»}

Studiens resultater indikerer at klinikkens jordmødre og leger legger stor vekt på å identifisere intrapartum feber og relevante prediktorer i fødsel, og følgelig fikk majoriteten korrekt behandling ved mistanke om infeksjon. 
Det var imidlertid en andel pasienter (28 prosent) hvor antibiotikabehandling ble initiert tidvis un $\varnothing$ dvendig eller på et tidligere stadium enn prosedyren tilsier. Det er rimelig å anta at årsaken til den utstrakte antibiotikabruken skyldes frykt for å overse en intrauterin infeksjon, snarere enn manglende kjennskap til prosedyren.

Våre funn samsvarer med flere studier som har unders $\varnothing \mathrm{kt}$ etterlevelse av evidensbaserte retningslinjer for antibiotikabehandling blant helsepersonell. Disse studiene konkluderte med at brudd på prosedyrene for antibiotikaforskrivning i stor grad går i retning av overbehandling. Årsaken var til dels mistillit til evidensbaserte retningslinjer og et føre-var-prinsipp $(22,23)$.

En viktig del av kvalitetssikringsarbeidet $\mathrm{i}$ fødselsomsorgen er å følge utviklingen og evaluere praksis (24). Vi finner at anbefalinger fra veilederen $i$ fødselshjelp og lokal prosedyre om feber under fødsel og chorioamnionitt ikke etterleves optimalt.

\section{«Rett behandling til rett pasient blir en viktig oppgave fremover.»}

$\varnothing \mathrm{kt}$ innsats for å redusere og optimalisere antibiotikabruken - rett behandling til rett pasient blir en viktig oppgave fremover for å minimere uheldige bivirkninger hos mor og barn og redusere utviklingen av resistens (25). Ved å følge anbefalte retningslinjer og prosedyrer vil unødvendig antibiotikabruk bli redusert.

\section{Styrker og svakheter ved studien}

Studien gir en oversikt over gjeldende praksis ved Fødeavdelingen på Ullevål sykehus. Ved gjennomgang av 621 journaler har vi for hvert enkelt kasus innhentet informasjon fra en stor populasjonsbasert fødselsdatabase. Det er tenkelig at det i enkelte journaler har forekommet feilaktig eller mangelfull dokumentasjon. 
Studien er en deskriptiv beskrivelse av et utvalg og har dermed ingen kontrollgruppe. Studien kan derfor heller ikke bidra til å besvare sammenhenger mellom maternelle og neonatale karakteristika, obstetriske variabler og risiko for feber under fødsel.

Studien er en tverrsnittsstudie og reflekterer klinisk praksis i en gitt tidsperiode. Studieperiode er forholdsvis kort på én måned, og resultatene må derfor tolkes i lys av dette. Enkelte fenomener varierer erfaringsvis fra måned til måned, og selv om antallet datapunkter er forholdsvis stort, kan resultatene likevel representere et utvalg som ikke kan generaliseres til andre populasjoner.

\section{Konklusjon}

Vi fant en høyere forekomst av intrapartum feber enn beskrevet i litteraturen. Våre funn viser at behandlingen av feber i stor grad ble utført i tråd med veilederen og den lokale prosedyren, men at det er utfordringer knyttet til overbehandling med antibiotika.

Det er viktig at avdelingen kjenner til i hvilken grad prosedyren etterleves, for å kunne utarbeide forbedringstiltak og senere vurdere effekten av tiltak som iverksettes.

\section{Referanser}

1. Ashwal E, Salman L, Tzur Y, Aviram A, BenMayor Bashi T, Yogev Y, et al. Intrapartum fever and the risk for perinatal complications - the effect of fever duration and positive cultures. J Maternal Fetal Neonatal Med. 2018;31(11):1418-25.

2. Chen K. Intrapartum fever. UpToDate. 2019. Tilgjengelig fra: https://www.uptodate.com/contents/intrapartum-fever (nedlastet 20.10.2019). 
3. Greenwell EA, Wyshak G, Ringer SA, Johnson LC, Rivkin MJ, Lieberman E. Intrapartum temperature elevation, epidural use, and adverse outcome in term infants. Pediatrics. 2012;129(2):e447-54.

4. Shatrov JG, Birch SC, Lam LT, Quinlivan JA, McIntyre S, Mendz GL. Chorioamnionitis and cerebral palsy: a meta-analysis. Obstetrics and Gynecology. 2010;116(2 Pt 1):387-92.

5. Towers CV, Yates A, Zite N, Smith C, Chernicky L, Howard B. Incidence of fever in labor and risk of neonatal sepsis. Am J Obstet Gynecol. 2017;216(6):596.e1-5.

6. Apantaku O, Mulik V. Maternal intra-partum fever. Am J Obstet Gynecol. 2007;27(1):12-5.

7. Riley LE, Celi AC, Onderdonk AB, Roberts DJ, Johnson LC, Tsen LC, et al. Association of epiduralrelated fever and noninfectious inflammation in term labor. Obstet Gynecol. 2011;117(3):588-95.

8. Goetzl L. Epidural analgesia and maternal fever: a clinical and research update. Curr Opin Anaesthesiol. 2012;25(3):292-9.

9. Tita A. Intra-amniotic infection (clinical chorioamnionitis or triple I). UpToDate. 2019. Tilgjengelig fra: https://www.uptodate.com/contents/intra-amnioticinfection-clinical-chorioamnionitis-or-triple-i (nedlastet 09.09.2019).

10. Anim-Somuah M, Smyth RM, Cyna AM, Cuthbert A. Epidural versus non-epidural or no analgesia for pain management in labour. Am J Obstet Gynecol. Jun. 2017;216(6):596.e1-5. Tilgjengelig fra: https://www.cochranelibrary.com/cdsr/doi/10.1002/146 51858.CDoo0331.pub4/information (nedlastet 20.02.2019). 
11. Curtin WM, Katzman PJ, Florescue H, Metlay LA, Ural SH. Intrapartum fever, epidural analgesia and histologic chorioamnionitis. J Perinatol. 2015;35(6):396-400.

12. Norsk gynekologisk forening. Veileder i fødselshjelp. Feber under fødsel og chorioamnionitt. Oslo: Den norske legeforening; 2020. Tilgjengelig fra: https://www.legeforeningen.no/foreningsledd/fagmed/ norsk-gynekologisk-forening/veiledere/veileder-ifodselshjelp/ (nedlastet 01.09.2020).

13. Randis TM, Polin RA, Saade G. Chorioamnionitis: time for a new approach. Curr Opin Pediatr. Apr. 2017;29(2):159-64. Tilgjengelig fra: https://journals.lww.com/copediatrics/Abstract/2017/04000/Chorioamnionitis_ti me_for_a_new_approach.7.aspx (nedlastet 15.10.2019).

14. Oslo universitetssykehus (OUS). Normal fødsel. Oslo: OUS; 2019. Tilgjengelig fra: http://ehandbok.oushf.no/document/27405 (nedlastet 02.03.2019).

15. Folkehelseinstituttet. Medisinsk fødselsregister for 2018. Oslo: Folkehelseinstituttet: 2019. Tilgjengelig fra: http://statistikkbank.fhi.no/mfr/ (nedlastet 15.09.2019).

16. Sultan P, David AL, Fernando R, Ackland GL. Inflammation and epidural-related maternal fever: proposed mechanisms. Anesth Analg. 2016;122(5):154653.

17. Kovo M, Schreiber L, Ben-Haroush A, Shor S, Golan A, Bar J. Intrapartum fever at term: clinical characteristics and placental pathology. J Matern Fetal Neonatal Med. 2012;25(8):1273-7. 
18. Seaward PG, Hannah ME, Myhr TL, Faine D, Ohlsson A, Wang EE, et al. International multicentre term prelabor rupture of membranes study: evaluation of predictors of clinical chorioamnionitis and postpartum fever in patients with prelabor rupture of membranes at term. Am J Obstet Gynecol. Nov. 1997;177(5):1024-9.

19. Sharpe EE, Arendt KW. Epidural labor analgesia and maternal fever. Clin Obstet Gynecol. 2017;60(2):365-74.

20. Goetzl L, Rivers J, Evans T, Citron DR, Richardson DE, Lieberman E, et al. Prophylactic acetaminophen does not prevent epidural fever in nulliparous women: a double-blind placebo-controlled trial. J Perinatol. Mai 2004;24(8):471.

21. Lavesson T, Källén K, Olofsson P. Fetal and maternal temperatures during labor and delivery: a prospective descriptive study. J Matern Fetal Neonatal Med. 2018;31(12):1533-41.

22. Gouvêa M, Novaes CdeO, Pereira DMT, Iglesias AC. Adherence to guidelines for surgical antibiotic prophylaxis: a review. Braz J Infect Dis. 2015;19(5):51724.

23. European Centre for Disease Prevention and Control. Systematic review and evidence-based guidance on perioperative antibiotic prophylaxis. Stockholm: ECDC; 2013. Tilgjengelig fra: https://www.ecdc.europa.eu/en/publicationsdata/systematic-review-and-evidence-based-guidanceperioperative-antibiotic (nedlastet 10.10.2019).

24. Helsedirektoratet. Et trygt fødetilbud. Kvalitetskrav til fødselsomsorgen. Oslo: Helsedirektoratet; 2012. Tilgjengelig fra: https://www.helsedirektoratet.no/veiledere/et-trygtfodetilbud-kvalitetskrav-til-fodselsomsorgen2012 (nedlastet 20.09.2019). 
25. Antibiotikasenteret for primærmedisin (ASP), Nasjonal kompetansetjeneste for antibiotikabruk i spesialisthelsetjenesten (KAS). Hva er antibiotikaresistens? [internett]. ASP, KAS; 14.10.2019 [sitert 22.10.2019]. Tilgjengelig fra:

https://www.antibiotika.no/hva-er-antibiotikaresistens/ 